Parents' Communication Work in the Management of Food Allergies

Jennifer J. Bute

Associate Professor

Department of Communication Studies

Indiana University-Purdue University Indianapolis

jibute@iupui.edu

Clarissa Bowers

Doctoral Student

Department of Communication Studies

Indiana University-Purdue University Indianapolis

clarbowe@iu.edu

Daniel Park

Department of Communication Studies

Indiana University-Purdue University Indianapolis

This project was funded by a Grant Improvement through Faculty Training (GIFT) award, sponsored by the School of Liberal Arts and the Office of the Vice Chancellor for Research at IUPUI. We would like to thank the food allergy parents who generously shared their stories with us.

This is the authors' manuscript of the work published in final form as:

Bute, J. J., Bowers, C., \& Park, D. (2021). Parents' Communication Work in the Management of Food Allergies. Health Communication, https://doi.org/10.1080/10410236.2021.1880051 


\begin{abstract}
The National Academies of Sciences, Engineering, and Medicine (NASEM, 2017) has identified food allergies as a critical public health issue that significantly affects quality of life for patients and their families. Despite the crisis-level status of food allergies, especially in children, there are currently no curative treatments. As a result, impacted families must learn how to carry the burden of disease management. Using an expanded application of the concept of communication work (Donovan-Kicken et al., 2012), this study features data from interviews with 26 parents of food allergic children and explores how parents navigate the nuances of food allergy maintenance while negotiating and preserving valued relationships and identities through everyday talk. Results revealed that parents used communication to legitimate food allergy, balance potential face-threats with identity and relational goals, and coordinate care with spouses. Due to the lack of therapeutic treatment options, we found that parents utilize communication work, which is both demanding and effortful, as a form of disease management.
\end{abstract}




\section{Parents' Communication Work in the Management of Food Allergies}

The National Academies of Sciences, Engineering, and Medicine has classified food allergies as a critical public health issue stating that "this chronic disease has not garnered the level of societal attention that it warrants" (NASEM, 2017, p. 22). Food allergies, which have the potential to be life-threatening, are an extraordinarily challenging disease that significantly impairs quality of life. As many as 15 million Americans have food allergies, including 1 in 13 U.S. children (NASEM, 2017). Despite the prevalence of food allergies in the U.S, only one FDA-approved treatment currently exists, an oral immunotherapy recently approved for initiation in peanut allergic children ages 4-17 years (Aimmune Therapeutic, 2020). Yet, this therapy is not curative and targets only a single allergen. Parents of food allergic children must manage their child(ren)'s condition through strict avoidance of allergens and constant vigilance for signs of an allergic reaction. Moreover, coping with a food allergy is an inherently social challenge that requires continuous communication when navigating all aspects of life that involve food (e.g., meal planning, parties, grocery shopping, holiday celebrations). In fact, food allergy parents have identified communicating with family and friends as one of the most difficult aspects of coping with their child(ren)'s food allergies (French, 2019), and patient advocacy organizations have explicitly called for more scholarly attention to such social challenges (Bute et al., 2018).

Although food allergies have clear social and relational implications for parents of food allergic children, scholars have not examined the management of the food allergy experience using the lens of communication scholarship. The purpose of this study was to explore how food allergy parents use communication to manage their child's health and avoid allergic reactions. In the following sections, we outline the relevance of the food allergy context for scholars of health 
communication, explain the theoretical underpinnings that guided our study, and describe results from in-depth qualitative interviews with food allergy parents ${ }^{\mathrm{i}}$. We conclude with theoretical and practical implications relevant for scholars, health care providers, and food allergy families.

\section{Communication and the Food Allergy Context}

The food allergy setting is a rapidly evolving health context. Insurance claims for foodinduced anaphylaxis rose 377\% between 2007 and 2017 (FAIR Health, 2017). Moreover, the landscape of treatment for food allergy is in flux with numerous therapeutic developments on the horizon, as evidenced by the Food and Drug Administration's 2020 approval of Palforzia, the first-ever therapeutic treatment for food allergy (Aimmune Therapeutic, 2020).

Yet, in the absence of widely available therapies, the management of food allergy is characterized by a state of ongoing vigilance to avoid allergic triggers and perpetual readiness in anticipation of an allergic reaction (Gupta, 2013). As such, food allergies place a significant relational, social, and financial burden on families, not to mention the physical burden patients endure when they experience anaphylaxis (Warren et al., 2020). Parenting a child with food allergies complicates and disrupts daily activities (Walkner et al., 2015). For families of young children, managing social events and relationships is an ongoing source of stress and anxiety as parents navigate birthday parties, family gatherings, field trips, and school lunches (Springston et al., 2010; Valentine \& Knibb, 2011). Caregivers of food-allergic children, particularly mothers, have reported that their quality of life suffers under the burden of managing food allergies (Cummings et al., 2010; Rouf et al., 2012). In addition, caring for children allergic to foods that are particularly difficult to avoid, such as egg, milk, wheat, and soy, as well as previous experience witnessing severe allergic reactions (Warren et al., 2020) further impairs quality of life (Howe et al., 2014; Ward \& Greenhawt, 2014). Finally, children with multiple food allergies 
require greater vigilance from parents, which has been associated with poorer psychosocial outcomes for parents (Warren et al., 2020).

Diminished quality of life in food allergy parents is related to the significant knowledge, watchfulness, and behavioral demands necessary to manage food allergies. Food allergy is a fundamentally social disease that requires communication for daily food selection and preparation and avoidance of allergenic foods. The social effects of food allergies also consist of identity management concerns like social stigma and strained relationships, including possible detrimental effects on family relationships and marriages (Walkner et al., 2015). In other words, effective management of food allergy demands high social skills (Rosenbaum, 2018). These communicative tasks can be overwhelming for parents who experience even a minimal level of social anxiety and can be exhausting and burdensome even for those parents who don't experience such anxiety (Rosenbaum, 2018). Communication is particularly vital when parents leave children in the care of others or when social events beyond the immediate family involve food. Conveying how to care for and feed a food allergic child is essential, as accidental exposures to food allergens occur frequently, even when children are under adult supervision, and occur more frequently when the supervising adult is not the child's parent or when adults ignore food labels (De Schryver et al., 2017; Fleisher et al., 2012). In these situations, children's lives are quite literally at stake. Although previous research has clearly demonstrated that social and communicative challenges affect quality of life for food allergy families (Ruof et al., 2012), the food allergy context has remained virtually untouched by health communication scholars. In the following section, we explain the central assumptions from communication theory that guided our investigation of parental communication about food allergies.

\section{Everyday Talk and the Communicative Labor of Food Allergy Management}


Our study of parents' communication about food allergies was informed by two theoretical assumptions. First, we were informed by scholarship calling for ongoing attention to everyday conversations about health, and second, we drew on work asserting that such communication is a form of labor for those managing serious or chronic health conditions.

While much of the scholarship exploring health communication investigates communication in clinical settings or explores the outcomes of strategic communication campaigns, the present study is informed by the claim that scholars must also attend to the "neglected box" in health communication research (Cline, 2003; 2011). That is, we must attend to the vitally important interpersonal conversations that happen outside of the medical encounter, by attending to the talk about health that unfolds in our everyday interactions with relational partners, relatives, and friends (Head \& Bute, 2017). Everyday interpersonal communication, whether such conversations involve tasks of household living, managing family events, budget and vacation planning, or other relatively mundane interactions, are exceptionally important in the case of food allergies because a) food allergies are relevant to any situation that involves food and b) conversations about food occur in daily interactions. Thus, in the present study, we focus on parents' everyday talk about food allergies.

The second assumption that drove our analysis is drawn from work by Donovan-Kicken and colleagues (2012) concerning the communicative labor involved in living and coping with a chronic illness. More specifically, we drew on the concept of communication work (DonovanKicken et al., 2012; Iannarino, 2018) to explore how food allergy parents navigate disease management while negotiating and preserving valued relationships and identities. The notion of “work" involved in managing serious or chronic illness originated in Corbin and Strauss's (1998) theory of illness trajectories. The original theory proposed three distinct and taxing lines of work 
comprised of tasks that patients and their loved ones perform to manage illness. These lines of work include: illness-related work (e.g., scheduling and attending doctor's appointments, medication management, physical therapy), biographical work (e.g., identity shifts to assimilate the illness into one's sense of self and ongoing life narrative), and the everyday-life work in which adults engage (e.g., grocery shopping, paying bills, caring for children). In their extension of Corbin and Strauss's (1998) theory, Donovan-Kicken and colleagues examined the communicative labor involved in managing cancer and argued that communication work is a separate and equally strenuous fourth line of work required to manage chronic illness. The labor involved in this form of talk is demanding and effortful, is often characterized by a sense of duty or obligation to share information about one's illness and treatments, involves preparation and planning, and often entails active and intentional efforts at message design (Donovan-Kicken et al., 2012). Communication work can necessitate a host of tasks, including disclosure, topic avoidance, solicitation or blocking of social support, and emotion management (DonovanKicken et. al, 2012; Iannarino, 2018). As Donovan (2019) noted, communication work is highly complex and multifaceted because it "entails informational, relational, and emotional efforts" for which most people are ill-equipped (p. 238). Based on these theoretical underpinnings, we explored the following research question:

RQ: What is the nature of communication work in everyday talk for food allergy parents?

\section{Methods}

Through in-depth qualitative interviews with 26 parents of children with food allergies, we explored how parents use communication in everyday talk with spouses, relatives, and friends to keep children safe and prevent allergic reactions. Researchers who study allergic disease have called for work that examines life with food allergies from a qualitative approach, 
which offers a rich and textured perspective that is missing from the relatively small literature on social aspects of food allergy (Gallagher et al., 2009). Qualitative work is essential for understanding the context in which patients and families manage allergic disease, with a goal of illuminating insights neglected or missing from quantitative research. Overreliance on quantitative work "risks eclipsing both the everyday social relations of allergic disease, and the prospect of in-depth investigation into that reality" (Gallagher et al., 2009, p. 1119).

\section{Recruitment and Sample}

We recruited parents of children ages 12 years and under with an allergy to at least one food. We targeted parents of this age group to seek the experiences of parents who still took the lead in handling their child's food allergies. We posted study information on Facebook groups for food allergy parents (securing permission from group administrators if required) and distributed flyers in pediatric allergy clinics and also to interviewees to employ snowball sampling. Interested parties contacted the first author to determine that they qualified for the study and then scheduled a time and location for an interview. Our final sample included 26 parents of food allergic children. Of the 26 parents who participated in the study, 21 were female, 5 were male, and these participants identified as White $(n=22)$, Asian $(n=2)$, Black $(n=1)$, and Hispanic $(n=1)$. All participants were part of a marital dyad, though only two dyads jointly participated in the study. In situations where both spouses of a dyad were participants, each spouse was interviewed separately to reflect their unique perspectives on communication work. Most parents had one food allergic child $(n=19)$; however, 5 participants indicated they had 2 food allergic children and 2 participants indicated they had 3 food allergic children that qualified under study parameters. Most participants parented child(ren) with multiple food allergies; only 8 parents reported that their child was allergic to just one food. Participation in this study was 
not limited to a specific type of allergy or to those with a formal diagnosis, as we wanted to capture the vast range of experiences of food allergy parents. Our sample included parents of children allergic to one or more of the 9 most common food allergens, which are peanut, tree nut, milk, egg, soy, wheat, shellfish, finfish, and sesame, as well as children allergic to less common allergens like kiwi, garlic, and pitted fruits.

\section{Data Collection Procedures}

The first author, who is herself the parent of a food allergic child, conducted all interviews. We embraced her lived experiences as a food allergy parent to inform the data collection and analysis process, recognizing the advantages of her unique lens (Ellingson, 2009). For instance, her experience in managing food allergies for her own son allowed her to establish immediate rapport with study participants, and a few of the participants were familiar with her work in the food allergy community. Participants were recruited both locally (through the allergy clinics and social media targeted to the local area) and out-of-state (via wider-scale social media groups), so 13 interviews were conducted in person (12 in a private campus interview space and one in the participant's home), 10 were conducted via telephone, and 3 were conducted via Skype. Interview length ranged from 40 to 75 minutes, with an average of 58 minutes per interview. Prior to the interview, participants completed a brief demographic questionnaire and a food allergy parental burden survey (results of the burden survey are not reported here). Parents who took part in face-to-face interviews completed these instruments immediately prior to the commencement of the interview. Participants who took part via phone or Skype received the instruments via email several days prior to the interview session and emailed completed documents to the first author. All participants received a \$25 retail gift card upon completion of the study. The interview guide was designed based on the first author's personal experiences and 
scholarly expertise in both food allergy and interpersonal health communication. To ensure that the guide captured a range of food allergy perspectives, a draft of the interview questions was reviewed by three food allergy parents who provided comments and suggestions, and the interview guide was revised accordingly. The final set of questions prompted parents to discuss topics that included their family's food allergy story, the daily management of food allergies, memorable conversations about their child(ren)'s allergies, and how they handled family and social events involving food. The first author audio-record all interviews and composed field notes at the conclusion of each session to note methodological observations and emerging theoretical insights. Interviews were transcribed by a professional transcription service and edited to remove any identifying information. Following recommendations from Tracy (2013), we fact-checked each transcript by listening to the recordings while reading the transcripts.

\section{Data Analysis}

We employed Tracy’s (2013) pragmatic, iterative approach in analyzing our data, an approach that unfolds over multiple rounds of analysis with an eye toward practical implications of the study findings. During the interview process, the first author began to notice themes related to the concept of communication work in parents' descriptions of everyday talk about food allergies. Based on these observations, two authors revisited the literature on communication work (e.g., Donovan-Kicken et. al, 2012; Iannarino, 2018), read 4 transcripts selected using a random numbers generator, and independently created a list of codes describing communication work in those 4 transcripts. The first author then drafted a codebook that included code names, descriptions of each code, and exemplars. Next, the first 2 authors tested the preliminary codebook by analyzing 2 additional transcripts, again selected using a random numbers generator. We met to discuss the coding and agreed on necessary revisions and 
clarifications, including grouping together first-level codes (Tracy, 2013) to better capture theoretically-informed codes (i.e., second-level codes) based on sensitizing concepts from studies of communication work. For instance, codes about wording choices were collapsed into a theme about legitimating food allergies. After we finalized the codebook, we uploaded transcripts to Dedoose for analysis and coded the remaining transcripts based on the final codebook.

\section{Findings}

Our results revealed the tedious, daunting, and sometimes fruitless nature of communication work as described by parents of young children with food allergies. We found that parents used communication to legitimate food allergy, manage their child's daily safety and care, and coordinate care with spouses while simultaneously attending to face-threats by balancing identity and relational goals. Despite these efforts, participants also described interactions in which communication work was futile. In the following sections we illuminate how parents engaged in the communication work that is central to food allergy management.

\section{How Parents Communicatively Legitimate Food Allergies}

Like Donovan-Kicken and colleagues (2012), we found that communication work is demanding, requiring a great deal of time and effort, effort that includes working to legitimate food allergies. Indeed, we found that a primary source of labor for food allergy parents is engaging in communication work to legitimate food allergy as a serious medical condition that requires attention, care, and accommodation. Parents repeatedly expressed their frustration that food allergies are trivialized, misunderstood, and neglected. As such, communication work was essential to ensuring that others, especially trusted adults, would take food allergies seriously and protect children accordingly. Parents employed intentional wording choices, distinguished 
between food allergies and food intolerances, and offered more detailed explanations for certain types of allergies. Some parents in our sample, like Greg, explained ongoing exasperation with trying to convince people that food allergies are a serious health condition:

I mean, even family members ... Like, until they saw the reaction, and where their mouths were just open. Like, they could not believe how crippling it was. And thinking of my wife's parents ... Really, not many people have seen the reaction. So, even close family members, it's still, you know, just taking our word for it, that it's severe.

Kara echoed this sentiment: "I think of my in-laws, who don't take it seriously, who think I'm crazy." Kara said she regularly emailed her in-laws articles about food allergy fatalities in an effort to legitimate her own daughter's food allergies.

\section{Using Intentional Word Choices}

One way that parents attempted to convey the gravity of food allergies was by using intentional wording, such as describing allergies as "life-threatening," or using the term "anaphylaxis" when describing their child's health condition. Parents sometimes had to invoke the specter of death, as Kara did when sharing articles, to implore people, even close family members, to understand and validate food allergies. Betty told a haunting story of threatening to keep her child from his grandparents if they kept refusing to remove peanuts from his reach: "If this keeps happening, you cannot see your grandson because you are going to kill him. And I think that really hit home that she could possibly kill him if she gave him this chocolate bar, you know?" Wendy explained how she legitimates food allergies by emphasizing the severity of reactions "in terms of that it could be anaphylactic, he could have trouble breathing, he could have a drop in blood pressure, and I definitely put more emphasis on the seriousness of it now."

\section{Explaining Allergy vs. Intolerance}


Legitimating food allergies also involved attempts to clarify the difference between an allergy and a food intolerance or sensitivity and noting how the term allergy is often used incorrectly or carelessly. "The main misconception was the thing was, they think it's a food intolerance and sensitivity. They don't get that no, it's one millionth of a particle can kill this kid and he's already had anaphylaxis," said Sarah. While a food allergy triggers an immune system response, a sensitivity or intolerance typically triggers a digestive system response (Gupta, 2013), though our participants found that people commonly use these terms interchangeably. In other words, some parents struggled to clarify that an allergy can trigger an anaphylactic reaction, while a sensitivity or intolerance cannot. Greg explained how "people use allergies as an umbrella for, 'I don't like it,' or 'It makes my stomach hurt,' making it taxing for parents to explain that food allergies include the looming potential for a life-threatening reaction, and that a temporary discomfort, like a stomach ache or digestive issues, is likely not a true allergy.

\section{Offering More Detailed Explanations for Some Allergies}

We also found that parents whose children had allergies other than peanut (e.g., milk, wheat) described more difficult and frustrating communication work than other parents, indicating that some food allergies require a different type of more detailed explanation than others to legitimate their gravity. Tyler, whose son has numerous allergies, including milk, put it this way:

I find when I have to explain it to somebody, I have to explain it in a paragraph, a sentence just won't work. To say he's allergic to milk, people don't think butter, they don't think margarine, they don't think cheeses. There's so much stuff that has milk in it, they just think oh, a glass of milk. He can't have a glass of milk. Or if I say he's allergic to milk, people will say, "Oh, I get a tummy ache too when I drink milk." And it's like, no, it's not an intolerance, 
it's a complete allergy. And so, I find to explain it to somebody requires like a little bit of back and forth and a little bit of a conversation.

Tyler used this explanation to illustrate that people don't always realize that milk can be a serious allergy and, thus, this particular allergy required a more in-depth conversation than his son's nut allergies. Malcolm, who has three food allergic sons, expressed a similar observation, emphasizing that people are more likely to take nut allergies seriously than they are other lesserunderstood food allergies: "When people think of peanuts they're like oh, you know they can have anaphylactic shock with this. I'm like, well, it can happen with milk. It can happen with egg and things like that." In fact, some parents of nut-allergic children acknowledged that they were "lucky" or "fortunate" that their child's allergen was more widely acknowledged than others.

\section{How Parents Communicatively Construct Safe Environments}

Communication work in food allergy management entails not only the burden of legitimating food allergy, but also the instructional, educational, and relational work of conveying how to keep food-allergic children safe. The communicative construction of safety included everything from ongoing reminders about dietary restrictions, food preparation, and carrying epinephrine to providing written lists of safe foods and demonstrating instructions for administering epinephrine. Although their children's safety was a primary goal, parents were keenly aware of the identity and relational implications of communication work.

\section{Giving Blunt Instructions}

In addition to the seemingly unending work of legitimating food allergies, parents also engaged in somewhat more mundane, though no less exhausting, communication work by delivering instructions to spouses, family, and friends about aspects of food allergy care. Amanda discussed giving direct and explicit instructions to her son's grandparents about his 
care: "They have a tradition where all the grandkids spend the night for Christmas night and parents all go out on the town and then come back. But like every night we're like, 'Here's the EpiPen, remember and no peanuts."' Jamie discussed managing a Thanksgiving dinner when relatives unexpectedly fried the turkey in peanut oil, and the efforts necessary to protect his nutallergic son. He and his wife communicated to everyone there, “'Don't kiss our kid, don't hug him after lunch.' That kind of thing." Audra recalled instructing her in-laws not to feed her son from their plates when they were dining out at a Greek restaurant, explaining, "When my son was probably two, shortly after he was diagnosed when they were feeding him stuff off their plate without even checking I was like, 'No you cannot do that."' Such message strategies that included little or no deference to the hearer (Brown \& Levison, 1987) were sometimes deemed necessary and were even directed to spouses. For instance, Cassie's husband would often snack on foods with her daughter's allergens late at night, causing Cassie to remined him, "You can have your snacks or whatever but you have to wash your hands, you have to clean everything up, if you spilled something on the floor you're sweeping and mopping the floor."

\section{Repeating the Same Message}

Parents recalled the repetitive nature of communication work when detailing issues likes cross-contact with allergenic foods or the complexity of understanding food labels. Kim recalled the challenge of getting people to grasp the risk of cross-contact, "Even if you have safe food for her, you just put it next to dip that she can't eat. And it took years to get people to understand." The issue of cross-contact required repetition, as it was hard for people to understand that when foods have come in contact with an allergen through shared utensils, dishes, serving trays, or other means, that makes the food unsafe. Parents described how difficult it is for people to grasp that even a tiny amount of an allergen can trigger anaphylaxis. "Just one bite," Cassie 
emphasized over and over, "one bite could kill them." Repetition was also necessary to explain label-reading. Eva recalled a recent Thanksgiving:

My mom had made a turkey and I said, "Well what did you put on the turkey?” And she's

like, "Oh, just olive oil and then I put this seasoning mix on it." And I'm like, "Did you make the spice one or was it like packaged?” And she's like, “Oh, it was packaged. It's just a few things." So, I looked it up and, I'm like, "Mom, it has soy in it, which is another thing he's allergic to."

Eva went on to educate her mother, yet again, on how to find "soy" on a food label.

\section{Requesting Food Information}

Eva's conversation with her mom ended with an educational moment, but it began with Eva seeking information, a common form of parental communication work in which parents sought information from other parties to determine food safety This sort of work involves making inquiries in everyday talk to get information about what food might be served at an event, how food has been prepared, ingredients in dishes, and so on. Elaine felt that she could never let her guard down when it came to her son's food: "Even when people are aware, there's no half asking. So now even when people give me something...I know that they know, but still I ask." Susie's son was so allergic to shellfish, that even cooking it in the same house was a hazard. When her son went to play at friend's home, Susie would call ahead and ask, "'I need to make sure you're not cooking shellfish in your house tonight or you didn't this morning' It's a conversation that you have with every parent before he ever goes anywhere." Seeking information included examining food for anything suspicious. "With my in-laws," Tyler said "because every meal we would go there, it's like, look at the vegetables. It's like, wait, something's glistening. Why are the vegetables glistening? 'What's on the vegetables?' It's like, 
"Oh, I put butter on it."” Butter is unsafe for Tyler's milk-allergic son. Anita recalled asking her mom about a dessert she almost fed to her nut-allergic child:

"What are on the top right there?" "Oh, those are nuts. I'll just wipe them off." I go, "You can't just wipe them off because you cannot be sure that you've gotten all of them," and I said, "Doesn't it have a nut crust?" "Oh yeah, I forgot about that."

The burden of constant vigilance and obligatory inquiries is clear in these examples, where just a moment of inattention puts children at risk.

\section{Reassuring Others}

While parents felt the weight of continuous vigilance, there were inevitably times when children were left in the care of friends and relatives. Yet, family members and friends are often concerned about caring for a food allergic child, and parents are faced with convincing them that they are up to the task. Parents sometimes spent considerable effort reassuring trusted adults that they were capable of temporarily caring for a food allergic child. Susie, whose son had allergies to 9 foods, narrated an experience indicative of this type of communication work:

My brother was very fearful of him. My brother has a little boy who's the same age as [son], and he has one who's two years younger than [son]. It would be awesome, like, "Hey, [her brother], can you take [son] for the weekend because you've already got boys that age. He can play. He'd be good, whatever." He was very fearful of having him there. We finally talked through it enough. He was so afraid of doing something wrong. Susie had to talk "enough" to build her brother's confidence in caring for her son. Her example also demonstrates how reassurance work often overlapped with education or instructional work, as well as the identity and relational goals at stake in such conversations.

\section{Attending to Face Wants}


As Susie's interaction with her brother suggests, communication work about food allergies involves more than conveying or requesting information, and part of constructing safe environments included attending to face wants (Brown \& Levinson, 1987). Parents expressed concern that requesting information about food, asking for accommodations, or attempting to educate other people could be face-threatening, and they described attempts to mitigate these face threats. In doing so, parents made conscious efforts to balance identity and relational concerns with keeping children safe.

Parents were keenly aware that food allergy accommodations, especially the expectation to administer epinephrine in the event of an emergency, are an imposition, or in the language of politeness theory (Brown \& Levison, 1987), such requests are a threat to negative face. Amanda understood that "it feels unfair to tell them [family] what they can and can't make," and Dana was careful to share resources and instructions "without seeming mean." At the same time, parents recognized how food is intertwined with deeply ingrained traditions. Jamie said:

People are so set in their ways about food, right? Like people have a recipe, that's their recipe. And like people love it, and they come to Christmas every year to eat it, and, "Oh my God, I make the best peanut brittle every year at Christmas, I give that to everyone, why wouldn't you take my peanut brittle?" So I can see people getting offended, but my God, if you've got somebody, that's deathly allergic to peanuts, like back off on your peanut brittle.

Jamie acknowledged that foods unsafe for his son carry significance for particular holidays or rituals, at the same time that a stubborn insistence to protect such traditions put his son at risk. Many parents were concerned about putting a damper on holidays and social events. As Greg put 
it, "We try to walk that line between looking out for our kids, but not being excessively overbearing, and impinging on everyone else's good time."

Not only did parents express concerns for threats to negative face, they also discussed identity concerns for both themselves and others. In discussing ongoing struggles with her mother-in law not understanding the severity of her daughter's tree nut and egg allergies, Kim recalled telling her, "It's not that I don't trust you. It's ... this is how severe it is, and nobody wants to be responsible for [daughter's name] ending up in the hospital." In fact, numerous parents in the sample understood how food allergies can threaten identity expectations for the grandparent role. As Sarah said, "Mom is so big on traditions and seeing things. It's the what she was expecting versus what is reality, that a grandparent should just be able to shower with goodies, sweets, their grandkids however they want, and she can't."

Parents simultaneously managed identity threats to others with their own identity concerns. Several mothers in the sample, including Angie, discussed resisting the urge to be "mama bear" or to turn "mean and nasty":

Trying to be mama bear and protect my little cub and then also on the same hand not wanting to challenge the face or make other people feel stupid or silly, or to impose on them, I guess, at the heart of it. They're having us over for dinner, they're cooking for us. That becomes tricky.

And Robin recalled the choice between appearing like a controlling, "heinous biotch" with her in-laws and allowing her milk-allergic daughter to take a bit of a potentially unsafe food.

\section{How Parents Coordinate Communication Work with Spouses}

All participants in our sample discussed organizing food allergy care with spouses. This type of work took the form of checking in, resolving disagreements, and dividing communicative 
labor. Our findings also suggest that mothers in our sample bore a larger share of the communicative burden.

\section{Checking In}

Part of communication work involved spouses talking with each other to manage food allergies. This work included checking in with each other about label-reading, determining the safety of food at social events, and discussing long-term issues, such as upcoming allergist appointments or possible therapeutic options. Malcolm said:

We rely on each other heavily to make it through. Whether it just be questions, what do you think about this, what do you think about that? Did you read the label? Yeah, I read the label. Do you want to double check the label?"

Similarly, Anita explained coordination with her husband at social gatherings, "When we're at places, we try to communicate like, 'Okay, I know this is safe, this is safe, this is safe, this is safe. Let them have this." Dana recalled standing in the kitchen with her husband and discussing proper storage of pizza with a nut-based pesto to separate it from their son's safe pizza, indicating how everyday tasks require communication work. Some wives in the sample described giving instructions to their husbands. For instance, Stacia frequently reminded her husband to take along safe snacks at ball games and other social events, and Natalie constantly reminded her husband not to leave the house without her daughter's EpiPens.

\section{Resolving Disagreements}

While most of parents in our study indicated that they were on the same page with their spouses when it came to food allergy management, there were moments of disagreement. Most of these centered on risk-taking, such as whether to let a child try a new food and under what circumstances to attend events where dangerous foods would or could be present, or even when 
to visit the ER in the event of an allergic reaction. Greg recalled disagreements with his wife over social and family gatherings because his daughter's allergies included milk, which is notoriously hard to avoid:

It usually would fall along those lines of, I want our family to go and do something, and she does not. And, for a mix of reasons, from me wanting to go, to feel like a normal family, and do normal family things. And, for her, not wanting to do things that may have additional risk.

Kara described disagreements with her husband as "there's a lot of just him being clueless because it's just who he is. So I've just learned over the years it's almost a battle not worth fighting." Parents in our sample did not describe serious arguments about food allergies, but often attributed what they labeled as conflicts to differences in personality, such as risk-taking preferences or (lack of) attention to detail.

\section{Dividing Labor}

In addition to deliberating with each other, spouses reported dividing the work. In some instances, spouses shared communication work equally, and the obligation of responsibility was communal. This division of talk typically fell along family lines. For instance, Kim asked her husband to handle food allergy conversations with his mom about upcoming holiday celebrations: "So I gave it to him and I'm like, "Tell her." However, we also found that mothers perceived themselves as doing more of the communication work and that most fathers in the sample admitted that their wives took the lead in food allergy management. For mothers in our study, this meant that they engaged in communication work with family members and friends, as well as with their husbands. Angie admitted to some frustration with these unending tasks, "But since [son's name]'s not outgrowing the allergy, I think it's time for Daddy to get a little bit more 
involved." Much of the uneven division of labor among spouses revolved around mothers as the family food allergy experts, so much so that husbands sometimes increased wives' communication work. Vanessa said, "He likes grocery shopping, so it was almost easier for me to do it, though, because he'd just call me the whole time. Can I get this brand? Can I get that brand? It was just exhausting to send him to the grocery store." And Stacia described her husband's forgetfulness that about food safety: "I'll have to remind him sometimes and he may remember but I'm always like, 'Remember [children's names] can't have that." We should acknowledge that some dads in the sample expressed dismay that food allergy moms get attention in a way that dads do not, so it could be that the efforts of dads are ignored in broader conversations, such a social media sites like "Food Allergy Moms" or the "No Nuts Moms Group.” As Malcolm put it, "I feel like food allergy dads are overshadowed."

\section{Accepting the Futility of Communication Work}

Some parents expressed a sense of futility about explaining food allergies. Some, like, Betty, voiced a general sense of futility: 'Don't get mad at people for not understanding, don't, don't hold it against them, it's not that they're being mean, and they just, they don't have to live it so they're just not gonna get it, you know."

“There's certain people ... I'm sure you know, who get it and certain ones who don't. You feel like you have the same conversation 100 million times," said Kim. In addition to a general sense that some people will never understand food allergies, participants identified specific relatives, mostly grandparents, who would just never "get" food allergies. Referring to his inlaws, Tyler explained, "It's not a conversation worth having anymore. They're gonna do things their own way." His mother-in-law had recently made a cake for their milk-allergic daughter, 
who described her mouth feeling funny after taking a single bite. It turned out that even after repeated reminders, his mother-in-law had not purchased the safe cake mix they had requested: And then my wife's like, "What type of box did you use?" And then she was trying to describe the box and she's like, "That's not the box," "Oh, I thought you meant the blue box," she's, so. It's just read the directions. It's just an unwillingness, just, I don't know. It's just a fine example I think right there. She just made it. Read the darn directions, all you gotta do. It would take them five seconds to look at the box and say, "Oh. This has milk in it." But they don't. It's just not a priority for them

The futility of repeating directions, requests, and explanations in an unending loop made parents feel as though they were "fighting upstream the whole way" and amplified communicative labor. As Kim said when recalling wearisome conversations with her motherin-law, "You just don't understand how much anxiety that causes."

\section{Discussion and Implications}

Despite the central role of interpersonal talk in the management of food allergies, the food allergy context remains virtually untouched by communication scholars. Using the lens of communication work (Donovan Kicken et al., 2012, Iannarino, 2018), we explored the multiple forms of communicative labor food allergy parents use to maintain children's health and safety.

\section{Theoretical Implications}

Our findings both coalesce with and extend the original conceptualization of communication work proposed by Donovan-Kicken and colleagues (2012). Like cancer patients in their study, parents in our sample described communication work that is demanding and effortful, sometimes involves planning and forethought, includes active and thoughtful message design (e.g., intentionally using the word "anaphylaxis"), and requires managing multiple goals 
to preserve desired identities and relationships. Moreover, just as cancer patients and their support persons have described sharing work with relational partners, or instances when relational partners took over work (Iannarino, 2018), food allergy parents also described dividing communication work, although this division was not always even, as mothers in our sample seemed to bear a larger burden of communication labor.

Our data also extend the conceptualization of communication work in previous research. Based on our findings, we contend that communication work is a form of illness-related work. While the original theory of illness trajectories (Corbin \& Strauss, 1987) suggested that illnesswork is typically task-oriented in the sense that in involves undertakings like adhering to a medication regimen, attending medical appointments, or making certain lifestyle adjustments, our findings suggest that communicative tasks like giving instructions, making inquiries, and even convincing others that an illness is real can be a necessary aspect of illness management. Food allergy is an example of a disease managed almost entirely through communication, and talking about food allergy is a required part of disease management. Our evidence suggests that parents of children with food allergies use communication to construct safety in the same way that other chronic conditions might require therapeutic regimens like medication. In the absence of widely available therapies for food allergies, health and safety are maintained, and thus the disease is managed, through strict avoidance of allergic triggers. Such avoidance is impossible without ongoing communication. While our findings support the contention that communication work is a distinct line of work required to cope with chronic illness, they simultaneously suggest that the nature of communication work and how cleanly that work can be distinguished from other forms of work can vary significantly depending on the nature of the disease context. 
Moreover, a pervasive form of communication work for parents in our study was working to legitimate their child's health condition. By using intentional wording, clarifying the difference between allergies and intolerances or sensitivities, working to explain specific types of lesser understood allergies, and combating misuse of the term "allergy," parents in our sample worked hard to convince people that food allergies are real and that they must be treated seriously. Like other invisible conditions, food allergy is a contested illness (Thompson \& Duerringer, 2020) that can remain so even after parents invest significant time and energy into convincing parties otherwise. In fact, scholars have suggested that working to legitimate a health condition, or what Werner \& Malterud, (2003) deem "credibility work," is especially taxing (Thompson \& Duerringer, 2020). While dismissal, disbelief, and delegitimization of illness are not new (Thompson \& Duerringer, 2020, Thompson \& Parsloe, 2019; Werner \& Malterud, 2003) in the case of food allergy contesting the condition could actually put lives at risk, and threaten the ability to manage the disease, especially for young children who might not have the verbal or cognitive capacity to advocate for themselves.

Although Donovan-Kicken and colleagues (2012) framed communication work as connected to a sense of duty or obligation, that sense of duty in their study was largely relational in nature (e.g., an obligation to tell relatives about a cancer diagnosis). The sense of duty and obligation is amplified for food allergy parents: the stakes are higher in these situations because communication is the primary means of disease management. The interpersonal talk required to manage a child's food allergies is a prominent, essential, and an often-cumbersome feature of parenting food allergic children. Miscommunication or the choice not to ask questions puts children at risk. However, some participants in our study experienced a sense of futility, the feeling that talking about food allergies with certain people seemed to make little or no 
difference in their ability, or perhaps willingness, to accommodate or assist with food allergy management. While Donovan-Kicken and colleagues (2012) found that patients and significant others perceived beneficial outcomes to engaging in communication work, as did our participants, some parents in our study seemed resigned to the fact that certain people would just never "get it" and could therefore never be trusted to fully understand and manage their child's food allergies.

\section{Practical Implications}

Scholars have called for improved education of all food allergy caretakers (e.g., Fleischer et al., 2012), especially nonparental caretakers, yet the message to simply educate or instruct others is vastly oversimplified. While there are existing resources that offer parents advice about talking to spouses, friends, and relatives — such as books by well-known food allergy experts (e.g., Gupta, 2013) and recommendations included on the Food Allergy Research and Education web site (https://www.foodallergy.org) — these resources are not currently as helpful as they could be in offering suggestions for communication because they are not grounded in communication theory and research. Existing resources are a good starting point in addressing the needs of food allergy parents, yet they tend to assume a "one size fits all" approach that does not reflect our findings. For example, some web sites, articles, and books offer advice such as, "Provide your family with educational resources," "Explain the allergy, which foods to avoid, and the safety precautions you follow at home," and "Don't take the bait but do communicate" (meaning that parents should avoid drama and conflict about food allergies.). This oversimplified advice tends to assume that if parents communicate clearly, then they will be understood, and their instructions will be followed. This approach ignores the fact that all communication is imbued with multiple meanings (Bute, 2009; Goldsmith, 2004), and that the same message might 
not work in every situation and with every person (Goldsmith, 2008). In the food allergy context, this means that clearly explaining a child's allergy to a grandparent might not be sufficient because that same message can threaten the expectations that a grandparent has for his or her role in the child's life. Telling a family member not to feed a child or to feed only certain foods is critical information to convey but can also be interpreted as demanding or hurtful by those who construe such messages as meaning that parents do not trust them to care for their child. Thus, talking about food allergies must be framed as an issue of communication competence, in which parents learn strategies for communicating their child's needs, and their child's specific allergy(ies), in ways that are both effective and appropriate (Spitzberg \& Cupach, 1989) and that attend to multiple, potentially competing goals (e.g., face-threats and identity concerns).

\section{Conclusion and Future Directions}

Our approach to this study was informed by the assumption that much of our communication about health unfolds in everyday talk (Cline 2003; 2011). As such, our analysis focused on conversations with friends and relatives. However, the scope of communication work about food allergy is inevitably even larger than the overwhelming array of conversations presented in the current analysis, as food allergy parents coordinate with schools, childcare providers, restaurants, health care providers, and more. Future work could expand on the scope of communication work in the food allergy context. Our interviews also suggested a gendered pattern in the division of communicative labor, which is consistent with studies reporting mothers as more stressed about food allergies (Cummings et al., 2010; Rouf et al., 2012). Perhaps one explanation for this increased stress is the taxing nature of communication work, and a closer examination of the gendered burden of caregiving in the food allergy context merits further exploration. Additional research could explore the relationship between communication 
work and the role of grandparents. Many participants in our study discussed communication work with a child's grandparents, and future research should draw on work in family communication to tease out the dynamics at play when working to explain food allergy management in these specific relationships.

Finally, as more therapies like Palforzia emerge, parents will face new forms of communication work. For instance, oral immunotherapies (OIT) like Palforzia are generally not considered curative in that patients cannot consume their allergen freely (Patrawala et al., 2020). The medication works by decreasing the likelihood of a severe anaphylactic reaction in the event of an accidental allergen exposure. Therefore, patients undergoing such therapies must still follow restricted diets and carry epinephrine. This regimen could be confusing for food allergy parents to explain to friends and relatives who might believe that a child undergoing OIT is no longer food-allergic. Perceptions of incoherent illness representations (Thompson \& Parsloe, 2019), like telling relatives your child is taking a drug for peanut allergy but still can't eat peanuts, could impede changing communication and maintenance regimens as parents and patients begin such therapies.

All in all, we maintain that applying the lens of communication work in the food allergy context extends previous theorizing that designated communication work as a distinct form of work. Moreover, our findings aid in understanding which communication facilitators and barriers future interventions for food allergy parents should address. 


\section{References}

Aimmune Therapeutic. (2020, January 31). FDA approves Aimmune's PALFORZIA ${ }^{\mathrm{TM}}$ as first treatment for peanut allergy. http://ir.aimmune.com/news-releases/news-release-details/fdaapproves-aimmunes-palforziatm-first-treatment-peanut-allergy

Brown, P., Levinson, S. C., \& Levinson, S. C. (1987). Politeness: Some universals in language usage. Cambridge University Press.

Bute, J. J. (2009). "Nobody thinks twice about asking": Women with a fertility problem and requests for information. Health Communication, 24(8), 752-763. $\underline{\text { http://doi.org/10.1080/10410230903265920 }}$

Bute, J. J., Broome, S. B., Marcus, J. N., Mikulcik, S., \& Vickery, B. (2018). Development of a patient-centric food allergy research program: A model for action. Allergy, 73(7), 15511553. https://doi.org/10.1111/all.13452

Cline, R. J. W. (2003). Everyday interpersonal communication and health. In T. L. Thompson, A. M. Dorsey, K. I. Miller, \& R. Parrott (Eds.), Handbook of health communication (pp. 285-313). Lawrence Erlbaum.

Cline, R. J. W. (2011). Everyday interpersonal communication and health. In T. L. Thompson, R. Parrott, \& J. F. Nussbaum (Eds.), The Routledge handbook of health communication (2nd ed., pp. 377-396). Routledge.

Corbin, J., \& Strauss, A. L. (1987). Accompaniments of chronic illness: Changes in body, self, biography, and biographical time. In J. A. Roth \& P. Conrad (Eds.), Research in the sociology of health care: The experience and management of chronic illness (Vol. 6, pp. 249-381). JAI Press. 
Cummings, A. J., Knibb, R. C., Erlewyn-Lajeunesse, M., King, R. M., Roberts, G., \& Lucas, J. S. (2010). Management of nut allergy influences quality of life and anxiety in children and their mothers. Pediatric Allergy and Immunology, 21(4 Pt. 1), 586-594. http://doi.org/10.1111/j.1399-3038.2009.00975.x

De Schryver, S., Clarke, A., La Vieille, S., Eisman, H., Morris, J., Lim, R., Gravel, J., \& BenShoshan, M. (2017). Food-induced anaphylaxis to a known food allergen in children often occurs despite adult supervision. Pediatric Allergy and Immunology, 28(7), 715-717. http://doi.org/10.1111/pai.12770

Donovan, E.E. (2019). The communication work of conversations about health and illness. In S.R. Wilson \& S.W. Smith (Eds.), Reflections on interpersonal communication research (pp. 231-250). Cognella.

Donovan-Kicken, E., Tollison, A. C., \& Goins, E. S. (2012). The nature of communication work during cancer: Advancing the theory of illness trajectories. Health Communication, 27(7), 641-652. http://doi.org/10.1080/10410236.2011.629405

Ellingson, L. L. (2009). Engaging crystallization in qualitative research: An introduction. Sage.

FAIR Health. (2017). Food Allergy in the United States: Recent Trends and Costs [White paper]. https://s3.amazonaws.com/media2.fairhealth.org/whitepaper/asset/Food\%20Allergy\%20Whit e\%20Paper\%20Final.compressed.pdf

Fleischer, D. M., Perry, T. T., Atkins, D., Wood, R. A., Burks, A. W., Jones, S. M., Henning, A. K., Stablein, D., Sampson, H. A., \& Sicherer, S. H. (2012). Allergic reactions to foods in preschool-aged children in a prospective observational food allergy study. Pediatrics, 130(1), e25-e32. http://doi.org/10.1542/peds.2011-1762 
French, J. (2019, November 12). When family doesn't get your child's food allergies. Allergic Living. https://www.allergicliving.com/2019/11/12/family-and-your-food-allergic-child/

Gallagher, M., Worth, A., \& Sheikh, A. (2009). Clinical allergy has much to gain from engagement with qualitative research. Allergy, 64(8), 1117-1119. http://doi.org/10.1111/j.1398-9995.2009.02065.x

Goldsmith, D. J. (2004). Communicating social support. Cambridge University Press.

Goldsmith, D. J. (2008). Brown and Levinson's politeness theory. In B. B. Whaley \& W. Samter (Eds.), Explaining communication: Contemporary theories and exemplars (pp. 219-236). Erlbaum.

Gupta, R. (2013). The food allergy experience: Real voices. Real disease. Real insights. Createspace Independent Publishing Platform.

Head, K. J., \& Bute, J. J. (2017). The influence of everyday interpersonal communication on the medical encounter: An extension of Street's ecological model. Health Communication, 33(6), 786-792. http://doi.org/10.1080/10410236.2017.1306474

Howe, L., Franxman, T., Teich, E., \& Greenhawt, M. (2014). What affects quality of life among caregivers of food-allergic children? Annals of Allergy, Asthma \& Immunology, 113(1), 6974. e2. http://doi.org/10.1016/j.anai.2014.04.016

Iannarino, N.T. (2018). “It's my job now, I guess": Biographical disruption and communication work in supporters of young adult cancer survivors. Communication Monographs, 85(4), 491-514. http://doi.org/10.1080/03637751.2018.1468916

National Academies of Sciences, Engineering, and Medicine. (2017). Finding a path to safety in food allergy: assessment of the global burden, causes, prevention, management, and public policy. National Academies Press. 
Patrawala, M., Shih, J., Lee, G., \& Vickery, B. (2020). Peanut oral immunotherapy: A current perspective. Current Allergy and Asthma Reports, 20, Article 14. http://doi.org/10.1007/s11882-020-00908-6

Rosenbaum, G. D. (2018) Psychosocial issues in food allergy: A role for psychologists. NJ Psychologist, 68(2), 10-12. https://issuu.com/lilmisschris/docs/2018 spring journal final e19a075ae5eba3

Rouf, K., White, L., \& Evans, K. (2012). A qualitative investigation into the maternal experience of having a young child with severe food allergy. Clinical Child Psychology and Psychiatry, 17(1), 49-64. http://doi.org/10.1177/1359104511415636

Springston, E. E., Smith, B., Shulruff, J., Pongracic, J., Holl, J., \& Gupta, R. S. (2010). Variations in quality of life among caregivers of food allergic children. Annals of Allergy, Asthma \& Immunology, 105(4), 287-294.e3. http://doi.org/10.1016/j.anai.2010.08.003

Spitzberg, B. H., \& Cupach, W. R. (1989). Handbook of Interpersonal Competence Research. Springer-Verlag.

Thompson, C. M., \& Duerringer, C. M. (2020). Crying wolf: A thematic and critical analysis of why individuals contest family members' health complaints. Communication Monographs. Advance online publication. http://doi.org/10.1080/03637751.2019.1709127

Thompson, C. M., \& Parsloe, S. (2019). "I don't claim to be the world's foremost expert, but...": How individuals "know" family members are not experiencing health issues as severely as they claim. Qualitative Health Research, 29(10), 1433-1446.

http://doi.org/10.1177/1049732319827518

Tracy, S. J. (2013). Qualitative research methods: Collecting evidence, crafting analysis, communicating impact. Wiley-Blackwell. 
Valentine, A. Z., \& Knibb, R. C. (2011). Exploring quality of life in families of children living with and without a severe food allergy. Appetite, 57(2), 467-474.

http://doi.org/10.1016/j.appet.2011.06.007

Walkner, M., Warren, C., \& Gupta, R. S. (2015). Quality of life in food allergy patients and their families. Pediatric Clinics, 62(6), 1453-1461. http://doi.org/10.1016/j.pcl.2015.07.003

Ward, C. E., \& Greenhawt, M. J. (2015). Treatment of allergic reactions and quality of life among caregivers of food-allergic children. Annals of Allergy, Asthma \& Immunology, 114(4), 312-318. http://doi.org/10.1016/j.anai.2014.12.022

Warren, C. M., Jiang, J., \& Gupta, R. S. (2020). Epidemiology and burden of food allergy. Current Allergy and Asthma Reports, 20, Article 6. https://doi.org/10.1007/s11882-020$\underline{0898-7}$

Werner, A., \& Malterud, K. (2003). It is hard work behaving as a credible patient: Encounters between women with chronic pain and their doctors. Social Science \& Medicine, 57(8), 1409-1419. https://doi.org/10.1016/S0277-9536(02)00520-8

\footnotetext{
i Throughout the manuscript, we sometimes use the term "food allergy parent" to refer to parents of children with food allergies. This label is used colloquially in the food allergy community and is an identity that is actively adopted and enacted by some parents of food allergic children.
} 